\title{
PAPER
}

\section{Head injury as a risk factor for Alzheimer's disease: the evidence 10 years on; a partial replication}

\section{S Fleminger, D L Oliver, S Lovestone, S Rabe-Hesketh, A Giora}

See Editorial Commentary, p 841

J Neurol Neurosurg Psychiatry 2003;74:857-862

See end of article for authors' affiliations

.....................

Correspondence to: Dr S Fleminger, Consultant Neuropsychiatrist, Lishman Brain Injury Unit, Maudsley

Hospital, Denmark Hill, London SE5 8AZ, UK;

s.fleminger@iop.kcl.ac.uk

Received 2 August 2002

In revised form

26 November 2002

Accepted

2 December 2002
Objective: To determine, using a systematic review of case-control studies, whether head injury is a significant risk factor for Alzheimer's disease. We sought to replicate the findings of the meta-analysis of Mortimer et al (1991).

Methods: A predefined inclusion criterion specified case-control studies eligible for inclusion. A comprehensive and systematic search of various electronic databases, up to August 2001, was undertaken. Two independent reviewers screened studies for eligibility. Fifteen case-control studies were identified that met the inclusion criteria, of which seven postdated the study of Mortimer et al.

Results: We partially replicated the results of Mortimer et al. The meta-analysis of the seven studies conducted since 1991 did not reach significance. However, analysis of all 15 case-control studies was significant (OR $1.58,95 \% \mathrm{Cl} 1.21$ to 2.06$)$, indicating an excess history of head injury in those with Alzheimer's disease. The finding of Mortimer et al that head injury is a risk factor for Alzheimer's disease only in males was replicated. The excess risk of head injury in those with Alzheimer's disease is only found in males (males: OR 2.29, $95 \% \mathrm{Cl} 1.47$ to 2.06 ; females: OR $0.91,95 \% \mathrm{Cl} 0.56$ to 1.47 ). Conclusions: This study provides support for an association between a history of previous head injury and the risk of developing Alzheimer's disease.
T he relation between head injury and the risk of Alzheimer's disease remains inconclusive. Several casecontrol studies suggest head injury is a risk factor for developing Alzheimer's disease and report odds ratios ranging from $3.5^{1}$ to $13.75 .^{2}$ Other studies have, however, failed to replicate these findings. ${ }^{3}$

The most convincing evidence to date in support of an association between head injury and Alzheimer's disease is the meta-analysis by Mortimer et al of seven case-control studies conducted before 1991. ${ }^{5}$ In this study, the raw data for each case-control study were collected directly from the original authors. Mortimer et al reported a relative risk of $1.82(95 \%$ confidence interval (CI) 1.26 to 2.67 ) for head injury with a loss of consciousness. ${ }^{5}$ The relative risk, when adjusted for a family history of dementing illness, education, and alcohol consumption, remained significant but was only true for males $(2.67,95 \%$ CI 1.64 to 4.41$)$ and not females (0.85, 95\% CI 0.43 to 1.70$)$.

In view of the equivocal findings from Mortimer et al's study, ${ }^{5}$ and knowing that further case-control studies have been reported, we aimed to replicate the findings of Mortimer et al using a systematic review of case-control studies conducted in the past 10 years. We also sought to review the evidence for a relation between APOE status and head injury as risk factors for Alzheimer's disease. We have primarily relied on the data presented in published papers and, consequently, were unable to analyse covariate risk factors such as alcohol consumption, family history of dementing illness, and education.

\section{METHODS}

\section{Inclusion criteria}

This study identified case-control studies that reported on head injury, or the interaction between head injury and APOE status, as risk factors for Alzheimer's disease. The inclusion criteria were developed on the basis of a comprehensive review of the literature, and consideration of the criteria used by Mortimer et $a l,{ }^{5}$ in order to identify the major sources of potential bias and the measures taken in an attempt to minimise such bias. Seven factors were identified as essential requirements for entry into this study:

(1) Head injury with loss of consciousness: We were interested in head injury of a severity that occurs infrequently and that is likely to produce neurological effect. Therefore, we required that studies defined head trauma in terms of the presence of loss of consciousness. By excluding lesser head injuries, studies should be less exposed to recall bias and less likely to find an association that merely reflects a consequence of the prodrome of the dementia. No time restriction was placed on the period of unconsciousness.

(2) Matching of case and control subjects: Two different types of matching have been utilised in case-control studies. In individual matching, each case is matched to a control on the basis of age, gender, and sometimes ethnic group, years of education, or community of residence. This type of matching leads to a more powerful analysis as the odds ratio is calculated from the number of case-control pairs discordant on the risk factor. In contrast, frequency or group matching ensures that the proportion of subjects of a certain age and gender are similar in the case and control groups. We required studies to have used either individual or group matching. We also allowed studies that had not actively matched but where there was no significant difference between the case and control groups with regard to pertinent demographic variables.

(3) Diagnostic criteria for Alzheimer's disease: We required that studies used the NINCDS-ADRDA criteria for probable or possible Alzheimer's disease or the DSM criteria to make a clinical diagnosis of the Alzheimer type.

(4) Inclusion criteria for controls: Control subjects had to meet predefined inclusion criteria that attempted to rule out the possibility of dementia.

(5) Symmetrical data collection: For the Alzheimer's disease subjects (case) an informant had to be used to provide data about a history of head injury. However, bias may occur if this information is not collected symmetrically when an informant is interviewed on behalf of the case but not on behalf of the 
control. To exclude this potential confound we required that data regarding previous head injury were collected from informants, both for the cases and controls.

(6) Recruitment of controls: Studies were excluded where controls were selected from psychiatric departments. The use of psychiatric controls addresses an alternative research question-does head injury specifically increase the risk of Alzheimer's disease rather than, for example, depression?

(7) Head injury occurred prior to the onset of Alzheimer's disease: It is essential that incidents of head injury in case subjects occurred before the onset of Alzheimer's disease and therefore we required studies to have explicitly stated that this was the case.

In addition to the inclusion criteria, we also noted whether studies fulfilled two further criteria, although these were not necessary for inclusion. Studies that met each criterion were collated and analysed in a sensitivity analysis to examine how the odds ratio was affected by imposing more stringent requirements.

(8) Head injury occurred at least X years prior to the onset of Alzheimer's disease: Head injuries occurring close to the onset of Alzheimer's disease may have occurred before the Alzheimer's disease was formally diagnosed but after significant cognitive and behavioural decline had occurred; the head injury may have been a result of the Alzheimer's disease. Therefore, it was important to note whether each study indicated that the head injury occurred prior to the onset of Alzheimer's disease by a period of at least $X$ years. The duration, $\mathrm{X}$ years, was not specified.

(9) Matched relationship of informant: Information bias may stem from the differential recall of case informants and control informants if they have a different relationship to the subject. To avoid this source of bias we demanded that the relationship of the informant interviewed on behalf of the case was the same as the relationship of the informant interviewed on behalf of the control. For example, if the informant for the case was the spouse, then the informant for the matched control was also the spouse.

\section{Identification of studies}

Searches were undertaken in Medline (1966 to August 2001), Embase (1980 to August 2001), and PsycINFO (1998 to August 2001) using a comprehensive search strategy. The strategy was divided into two components; component A identified papers relating to "Alzheimer's disease" or "apolipoprotein E". This was combined, using the Boolean operator AND, with component $\mathrm{B}$, which identified papers relating to "head injury" or "risk factors". As an indication of quality, we required that the search strategy successfully retrieved the 11 case-control studies identified by Mortimer et $a l^{5}$ and therefore, the strategy was systematically tested and refined. In addition to the electronic search, the reference lists of recent review articles were hand searched. There were no language restrictions.

The search process generated 19370 papers, including duplicates, which were then screened by two independent reviewers (DLO, AG). Reasonable, but wide, inclusion criteria were applied when selecting papers. Not only were potential data papers extracted, but also were relevant background papers, review articles, and papers where only a title was provided. The reviewers achieved a good level of concordance. Of the 357 papers selected for further in depth review, 90 were identified by both of the reviewers; these contained 14 of the 15 studies that were subsequently included in the metaanalysis. The remaining paper was identified in the second part of the search strategy (reference list search).

The 357 papers were retrieved in full and were once more screened for eligibility, this time by a single reviewer who imposed narrow inclusion criteria. For a paper to be included,

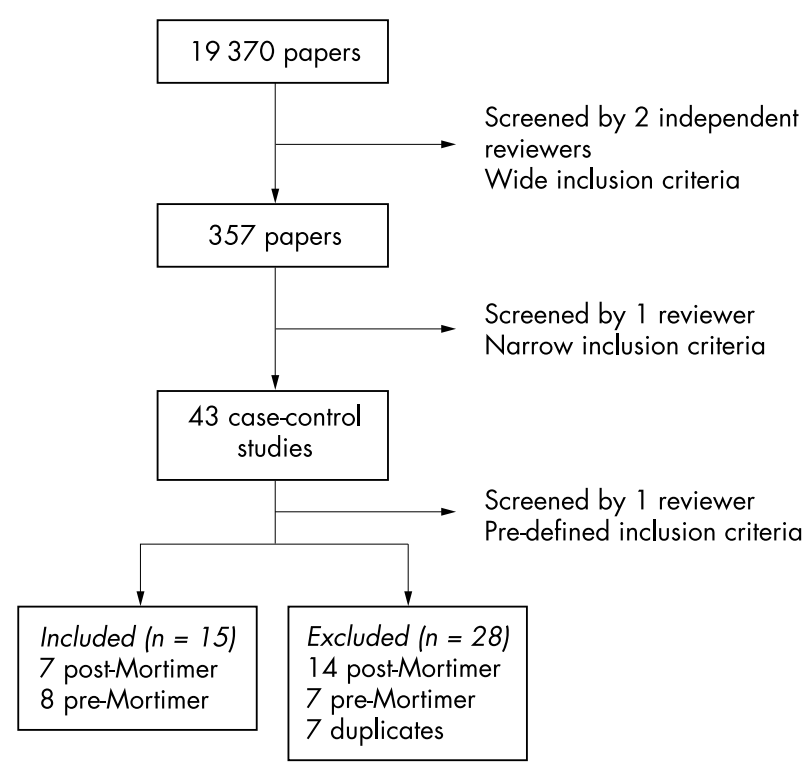

Figure 1 Flow chart depicting identification of case-control studies.

it had to have used a case-control design and investigated head injury or the interaction between head injury and APOE status as risk factors for Alzheimer's disease.

Forty three case-control studies were identified, of which 15 were conducted prior to 1991 (referred to as pre-Mortimer studies), 21 were published after 1991 (referred to as post-Mortimer studies), and seven amounted to duplicates as they presented data already reported elsewhere. The references cited by these studies were hand searched and the title and authors were entered into a Web of Science citation search. Only one additional paper was identified.

Of the 43 case-control studies identified, 21 studies that did not fulfil the above inclusion criteria, and the seven duplicate studies were excluded. Details of these studies can be found in the appendix. Of the remaining 15 papers, ${ }^{1246-17}$ seven had been conducted since 1991, all of which met our inclusion criteria.

\section{Statistical analysis}

Odds ratios with confidence intervals were computed for each case-control study, using the method for paired or independent samples, depending on whether controls were individually matched to cases. Exact confidence intervals were obtained. ${ }^{18}$ The meta-analyses were based on the log odds ratios and their standard errors as determined from the logarithms of the upper and lower bounds of the confidence intervals. After testing for heterogeneity in effect sizes between studies using a $\chi^{2}$ test, fixed effects meta-analysis was carried out unless there was significant heterogeneity at the $5 \%$ level, in which case random effects meta-analysis was used. All analyses were carried out in Stata $7 .^{19}$

\section{RESULTS}

The odds ratios and their $95 \%$ confidence intervals are given in table 1 for all subjects and by sex in table 3. There was no significant heterogeneity between odds ratios for all subjects $(\mathrm{Q}=12.39, \mathrm{df}=14, \mathrm{p}=0.58)$, or for females $(\mathrm{Q}=1.88$, $\mathrm{df}=6, \mathrm{p}=0.93)$ or males $(\mathrm{Q}=4.54, \mathrm{df}=7, \mathrm{p}=0.72)$. The results of the meta-analyses for all subjects, females and males, are given in table 2, where sensitivity analyses and separate meta-analyses for the post-Mortimer and preMortimer studies are also reported. Figure 2 shows the individual and combined odds ratios for all studies.

Only two studies examined the interaction between head injury and APOE status as risk factors of Alzheimer's disease, and therefore meta-analysis of this data was not possible. 
Table 1 Odds ratios for each of the 15 studies data

\begin{tabular}{|c|c|c|c|c|c|c|c|}
\hline 1st author & Quality* & $\mathrm{Cs}+\dagger$ & Cs- $-\ddagger$ & $\mathrm{Cnt+}$ & Cnt- & Odds ratio & $95 \% \mathrm{Cl}$ \\
\hline \multicolumn{8}{|l|}{ Pre-Mortimer studies } \\
\hline Mortimer (1985) & $P$ & 20 & 54 & 11 & 108 & 3.64 & 1.52 to 8.99 \\
\hline Amaducci (1986) & $P$ & 7 & 106 & 5 & 203 & 2.68 & 0.71 to 10.95 \\
\hline Chandra (1987) & $Q$ & 6 & 51 & 1 & 56 & 6.00 & 0.73 to 276.02 \\
\hline Chandra (1989) & $P, Q$ & 5 & 269 & 4 & 270 & 1.25 & 0.27 to 6.30 \\
\hline Broe (1990) & p & 8 & 162 & 6 & 164 & 1.33 & 0.41 to 4.66 \\
\hline Ferini-Strambi (1990) & $P$ & 5 & 58 & 10 & 116 & 1.00 & 0.26 to 3.39 \\
\hline Graves (1990) & $P, Q$ & 19 & 111 & 8 & 122 & 2.61 & 1.04 to 7.15 \\
\hline van Duijn (1992) & $P$ & 22 & 176 & 17 & 181 & 1.33 & 0.65 to 2.77 \\
\hline \multicolumn{8}{|l|}{ Post-Mortimer studies } \\
\hline Li (1992) & $Q$ & 1 & 69 & 2 & 138 & 1.00 & 0.09 to 11.03 \\
\hline Fratiglioni (1993) & $P, Q$ & 4 & 84 & 25 & 232 & 0.44 & 0.11 to 1.34 \\
\hline CSHA (1994) & $p^{\prime}$ & 13 & 149 & 27 & 393 & 1.27 & 0.58 to 2.63 \\
\hline Forster (1995) & & 22 & 87 & 16 & 93 & 1.50 & 0.68 to 3.41 \\
\hline Rasmusson (1995) & $P, Q$ & 4 & 64 & 1 & 33 & 2.06 & 0.19 to 104.59 \\
\hline O'Meara (1997) & & 32 & 317 & 16 & 326 & 2.06 & 1.07 to 4.09 \\
\hline Tsolaki (1997) & & 14 & 47 & 15 & 54 & 1.07 & 0.43 to 2.66 \\
\hline
\end{tabular}

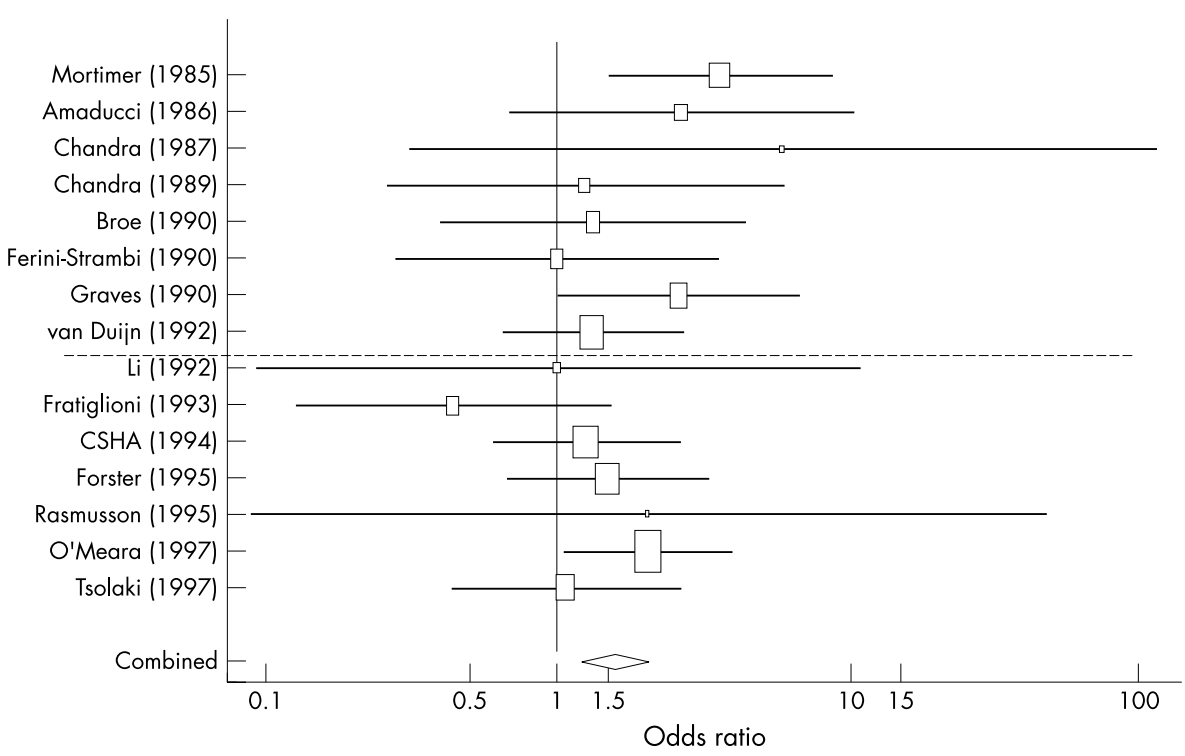

Figure 2 Odds ratio and $95 \%$ confidence intervals for each of the 15 studies and for all studies combined. An odds ratio of $>1$ (reference line) indicates more head injuries in the Alzheimer's disease cases. Pre-Mortimer studies are separated from post-Mortimer studies by the horizontal dashed line. The areas of the boxes are proportional to the inverse variances of the estimated log odds ratios.

The meta-analyses of all 15 studies and all subjects gave an odds ratio estimate of 1.58 (95\% CI 1.21 to 2.06 ). The first sensitivity analysis considered only those 10 studies that required head injury to have occurred $\mathrm{X}$ years prior to onset of Alzheimer's disease (labelled $\mathrm{P}$ in table 1). The pooled odds ratio was estimated as 1.56 (95\% CI 1.12 to 2.18 ), which was similar to the odds ratio for all 15 studies. The second sensitivity analysis considered only those studies where cases and controls were matched for informant type. The combined odds ratio was estimated as 1.42 (95\% CI 0.75 to 2.67 ) which was somewhat lower than that for all studies. When we analysed only the seven post-Mortimer studies, the odds ratio fell to 1.35 (95\% CI 0.94 to 1.94 ) and was no longer significant (table 2).

Finally, we have looked at the odds ratio for men and women (table 3). This analysis confirmed the findings of Mortimer $e t a l^{5}$ that the odds ratio for head injury is only increased in men (OR 2.26; $95 \%$ CI 1.13 to 4.53 ) and not in women (OR 0.92 ; $95 \%$ CI 0.53 to 1.59 ) (table 2 ).
Table 2 Results of fixed effects meta-analyses

\begin{tabular}{llllc}
\hline & $\begin{array}{l}\text { Number } \\
\text { of studies }\end{array}$ & $\begin{array}{c}\text { Odds } \\
\text { ratio }\end{array}$ & $95 \% \mathrm{Cl}$ & p value \\
\hline All studies & 15 & 1.58 & 1.21 to 2.06 & 0.001 \\
P only & 10 & 1.56 & 1.12 to 2.18 & 0.01 \\
$\begin{array}{l}\text { Q only } \\
\text { Post-Mortimer }\end{array}$ & 6 & 1.42 & 0.75 to 2.67 & 0.28 \\
$\begin{array}{l}\text { Pre-Mortimer } \\
\text { Females* }\end{array}$ & 8 & 1.35 & 0.94 to 1.94 & 0.10 \\
$\quad \begin{array}{l}\text { All studies } \\
\quad \text { Post-Mortimer }\end{array}$ & 7 & 1.90 & 1.29 to 2.81 & 0.001 \\
$\begin{array}{l}\text { Males† } \\
\quad \text { All studies }\end{array}$ & 8 & 0.91 & 0.56 to 1.47 & 0.69 \\
$\quad$ Post-Mortimer & 4 & 0.92 & 0.53 to 1.59 & 0.75 \\
\hline
\end{tabular}

*Female data: in Rasmusson (1995) neither cases nor controls had had a head injury so the odds ratio cannot be computed. †Male data: Fratiglioni (1993) had an estimated odds ratio of 0 and could therefore not contribute to the meta-analysis. 
Table 3 Odds ratios for female and male data

\begin{tabular}{|c|c|c|c|c|}
\hline \multirow[b]{2}{*}{1 st author } & \multicolumn{2}{|c|}{ Female } & \multicolumn{2}{|l|}{ Male } \\
\hline & OR & $95 \% \mathrm{Cl}$ & OR & $95 \% \mathrm{Cl}$ \\
\hline \multicolumn{5}{|l|}{ Pre-Mortimer studies } \\
\hline Mortimer (1985) & $-^{*}$ & - & 3.64 & 1.52 to 8.99 \\
\hline Broe (1990) & 0.50 & 0.01 to 9.60 & 1.75 & 0.44 to 8.15 \\
\hline Ferini-Strambi (1990) & 1.54 & 0.21 to 9.63 & 0.64 & 006 to 3.96 \\
\hline \multicolumn{5}{|l|}{ Post-Mortimer studies } \\
\hline van Duijn (1992) & 0.74 & 0.20 to 2.51 & 1.99 & 0.76 to 5.51 \\
\hline Fratiglioni (1993) & 0.58 & 0.14 to 1.83 & 0.00 & 0.00 to 1.93 \\
\hline CSHA (1994) & 1.26 & 0.42 to 3.45 & 1.35 & 0.39 to 4.11 \\
\hline Rasmusson (1995) & $-\dagger$ & - & 1.76 & 0.16 to 91.21 \\
\hline O'Meara (1997) & 1.11 & 0.44 to 2.85 & 4.18 & 1.45 to 14.69 \\
\hline Tsolaki (1997) & 0.62 & 0.17 to 2.20 & 2.01 & 0.49 to 8.40 \\
\hline
\end{tabular}

\section{DISCUSSION}

This study has partially replicated the main findings of Mortimer et al. ${ }^{5}$ There was no significant association between head injury and Alzheimer's disease in the seven studies conducted after Mortimer et al, in contrast to the eight studies included in the Mortimer et al meta-analysis. However, overall the 15 studies showed a significant association with an odds ratio of 1.58 (95\% CI 1.21 to 2.06), somewhat lower than the relative risk of 1.82 (95\% CI 1.26 to 2.67 ) reported by Mortimer et al. On the other hand, Mortimer et al's finding that the association between head injury and Alzheimer's disease was present only in males, was replicated. For males we observed an odds ratio of 2.26 and for females an odds ratio of 0.92 . These findings are very similar to Mortimer et al's study, which reported an estimated relative risk of 2.67 for males and a relative risk less than 1 for females.

A possible explanation for the gender difference in the risk of Alzheimer's disease following head injury is the role of the female hormones, oestrogen and progesterone. Animal models of stroke and traumatic brain injury (TBI) have provided evidence to suggest that these hormones may confer a neuroprotective and neuroregenerative effect. ${ }^{2021}$ For example, Bramlett and Dietrich, ${ }^{22}$ using an animal model of TBI, found contusion volume was significantly smaller in adult female rats than in male and ovariectomised female rats. The variation in circulating endogenous hormones was provided as an explanation for the observed differences in the extent of brain damage. Also, oestrogen has been implicated as a protective factor in the development of Alzheimer's disease. ${ }^{23-25}$ Therefore, it is possible that females are protected from Alzheimer's disease after head injury due to the protective effects of the female hormones.

This study was unable to review the relation between head injury and APOE gene status as risk factors for Alzheimer's disease. Only two studies that investigated this relation using a case-control design were identified. Mayeux et al $^{26}$ found that patients with at least one APOE $\epsilon 4$ allele and a history of head injury had a 10-fold increased risk of developing Alzheimer's disease. No association was found between head injury and Alzheimer's disease in the absence of APOE $\epsilon 4$ allele. In contrast, O'Meara et $a l^{15}$ found that APOE $\epsilon 4$ allele had little effect on the observed association between head injury and risk of Alzheimer's disease. However, O'Meara et al ${ }^{15}$ noted that the low rate of head injury reported by control subjects might have hindered the study's power to detect an interaction between head injury and APOE $\epsilon 4$.

The relation between head injury and Alzheimer's disease has also been examined through population based cohort studies that prospectively assess the risk of Alzheimer's disease following head injury. The historical cohort study of
Plassman $e a^{27}$ found an increased risk of Alzheimer's disease in World War II veterans who had sustained either a moderate (hazard ratio (HR) 2.32; 95\% CI 1.04 to 5.17 ) or severe head injury (HR 4.51 ; $95 \%$ CI 1.77 to 11.47 ) but not a mild head injury. The absolute rate of dementia observed in the sample as a whole, mean age at follow up of 75.8 years, was low at less than $5 \%$. In contrast, other cohort studies have failed to find evidence for an increased risk of Alzheimer's disease following head trauma. ${ }^{28-30}$ Nemetz et al ${ }^{29}$ identified people who had sustained a head injury during the period 1935-84 and used the resources of the Rochester Epidemiology Project, a computerised medical linkage system, to identify those who developed Alzheimer's disease prior to 1 June 1988, last contact, or death. Nemetz et $a l^{29}$ found that the number of individuals with head injury who later developed Alzheimer's disease was not significantly higher than the incidence of Alzheimer's disease in Rochester, Minnesota.

An advantage of the cohort design is that it removes many of the biases that plague case-control studies. ${ }^{31}$ The use of medical records to document the occurrence of head injury removes the need to rely on retrospective informant reports, and thus the data for case and control subjects is more likely to be of equal accuracy and precision.

On the other hand, there are several biases that may be present using case-control methods. For example, recall bias may arise because the informants of Alzheimer's patients may more readily recall a previous head injury than informants of control subjects, due to a need to account for their loved one's illness, ${ }^{7}$ or as a result of cues within the hospital environment. Further, the recall of a spouse informant may be more precise than that of other family members due to the duration and quality of contact. ${ }^{232}$ Hence, the information provided by case informants and control informants may differ significantly in quality. These issues are further exacerbated by differing definitions of head injury, the lack of a standard method for assessing the severity of head injuries, ${ }^{27}$ the potential for the misclassification of Alzheimer's disease, ${ }^{33}$ and the fact that many case-control studies lack the statistical power necessary to detect an association with head injury. ${ }^{58}$

The potential for bias to confound interpretation of the results of individual case-control studies is of major concern. This is illustrated by the study of Niino et al study ${ }^{34}$ which explored the association between a large number of potential risk factors and Alzheimer's disease. Nearly all of the factors investigated were found to be more common in patients with Alzheimer's disease, suggesting reporter bias may have confounded the results. In Mortimer et al's review, relative risks for studies of head injury with loss of consciousness compared to those for head injury of any severity were in the opposite direction to what one would predict. In the latter case, relative risk ranged from 2.40 to 18.0 and in the former, 
from 1.17 to 6.01 . These findings are compatible with reporting bias (mild injuries are probably more prone to reporter bias) or Alzheimer's disease playing a causative role in the occurrence of head injury.

In order to explore the effects of bias, we conducted a sensitivity analysis to examine whether imposing more stringent inclusion requirements, and thus minimising the possibility of bias still further, had the predicted affect on the odds ratio. The first restriction required studies to have recruited subjects with a head injury that occurred a specified period before the onset of Alzheimer's disease-that is, the injury was sustained at least $X$ years before the onset of Alzheimer's disease. The purpose of this analysis was to minimise the artefact from Alzheimer's disease causing the head injury. A reduction in the odds ratio on exclusion of these studies would be compatible with the findings being to due to this artefact. In fact, exclusion of these studies was found to have little effect on the odds ratio.

The other restriction, relating to recall bias, required studies to have matched, either individually or by group, the relationship of the informant to the case and control subject. One possible hypothesis is that Alzheimer's patients tend to be accompanied by their spouse, whereas the control subjects bring all comers to act as their informant. This would mean Alzheimer's patients would be more likely to have an informant who is better able to remember what happened many years ago. This artefact would therefore increase the odds ratio. However, Mortimer $e t ~ a l^{5}$ found that the relative risk for head trauma increased slightly when studies that had not matched informant type were excluded (RR 2.13,95\% CI 1.37 to 3.42). In the present study, analysis after removal of studies exposed to this bias, showed a reduction in odds ratio to a non-significant level. Unfortunately, when we attempted to perform sensitivity analyses of the male data, only two studies were left, ${ }^{211}$ one of which found a substantially increased and one a substantially decreased odds ratio.

In summary, the findings of the present study provide support for an association between head injury and the risk of Alzheimer's disease only in males. In light of the inherent complications in conducting case-control studies, future work should consider the use of population based cohort designs that rely on medical records to document head injury history.

\section{APPENDIX: EXCLUDED STUDIES}

Reasons for exclusion detailed in square parentheses [].

1. Barclay LL, Kheyfets S, Zemcov A, et al. Risk factors in Alzheimer's disease. In: Fisher A, Hanin I, Lauchman C, eds. Alzheimer's and Parkinson's disease. New York: Plenum Publishing, 1986. [Unable to establish the severity of the head injury, diagnostic criteria, whether head injury in the cases occurred prior to the onset of $\mathrm{AD}$, and if data collection was symmetrical]

2. Bidzan L, Ussorowska D. Risk factors for dementia of Alzheimer type. Psychiatria Polska 1995;29(3, suppl):147-52. [Unable to establish the severity of the head injury, whether head injury in the cases occurred prior to the onset of $\mathrm{AD}$, and if data collection was symmetrical]

3. Bratsun AL. [Risk factors of dementia Alzheimer's type]. [Russian]. Zhurnal Nevrologii $i$ Psikhiatrii Imeni S.S. Korsakova 1998;98:16-20. [Unable to establish whether data collection was symmetrical]

4. French LR, Schuman LM, Mortimer JA, et al. A case-control study of dementia of the Alzheimer type. Am J Epidemiol 1985;121:414-21. [Presents the same data reported by Mortimer et al (1985)]

5. Guo Z, Cupples LA, Kurz A, et al. Head injury and the risk of AD in the MIRAGE study. Neurology 2000;54:1316-23. [Unable to establish whether head injury in the cases occurred prior to the onset of $\mathrm{AD}$. Case and control subjects were not matched (spouse controls)]

6. Hall K, Gureje O, Gao S, et al. Risk factors and Alzheimer's disease: a comparative study of two communities. Aust $N Z J$ Psychiatry
1998;32:698-706. [Unable to establish the severity of the head injury or whether head injury in the cases occurred prior to the onset of AD. Case and control subjects were not matched]

7. Harwood DG, Barker WW, Loewenstein DA, et al. A cross-ethnic analysis of risk factors for $\mathrm{AD}$ in white Hispanics and white non-Hispanics. Neurology 1999;52:551-6. [Case and control subjects were not matched. Data collection was not symmetrical]

8. Henderson AS, Jorm AF, Korten AE, et al. Environmental risk factors for Alzheimer's disease: their relationship to age of onset and to familial or sporadic types. Psychol Med 1992;22:429-36. [Presents the same data reported by Broe et al (1990)]

9. Heyman A, Wilkinson WE, Stafford JA, et al. Alzheimer's disease: a study of epidemiological aspects. Ann Neurol 1984;15:335-41. [Considered head trauma of any severity]

10. Hofman A, Schulte W, Tanja TA, et al. History of dementia and Parkinson's disease in lst-degree relatives of patients with Alzheimer's disease. Neurology 1989;39:1589-92. [Presents the same data as reported by van Duijn (1992)]

11. Kokmen E, Chandra V, Schoenberg BS. Trends in incidence of dementing illness in Rochester, Minnesota, in three quinquennial periods, 1960-1974. Neurology 1988;38:975-80. [Presents some of the data reported by Chandra et al (1989)]

12. Kondo K, Nimo M, Shido K. A case-control study of Alzheimer's disease in Japan-significance of life-styles. Dementia 1994;5:314-26. [Data collection was not symmetrical. Unable to establish whether there was a formal examination of the controls to rule out dementia]

13. Kondo K, Yamashita I. A case-control study of Alzheimer's disease in Japan: association with inactive psychosocial behaviours. In: Hasegawa K, HommaK, eds. Psychogeriatrics, biomedical and social advances. Amderstam: Excerpta Medica, 1990. [Presents some of the data reported by Kondo et al (1994)]

14. Mayeux R, Ottman R, Maestre G, et al. Synergistic effects of traumatic head injury and apolipoprotein-epsilon 4 in patients with Alzheimer's disease. Neurology 1995;45:555-7. [Data collection was not symmetrical.]

15. Mayeux R, Ottman R, Tang MX, et al. Genetic susceptibility and head injury as risk factors for Alzheimer's disease among communitydwelling elderly persons and their first-degree relatives. Ann Neurol 1993;33:494-501. [Data collection was not symmetrical. Case and control subjects were not matched]

16. Mendez MF, Underwood KL, Zander BA, et al. Risk factors in Alzheimer's disease: a clinicopathologic study. Neurology 1992;42(4 I):770-5. [A clinicopathologic study: all of the case and control subjects were deceased]

17. Niino N, Ijima S, Mizoguchi T, et al. [A case-control study of clinically diagnosed Alzheimer type dementia]. [Japanese]. Nippon Ronen Igakkai Zasshi [Japanese Journal of Geriatrics] 1990;27:693-8. [Unable to establish the severity of the head injury]

18. Paschalis C, Polychronopoulos P, Lekka NP, et al. The role of head injury, surgical anaesthesia and family history as aetiological factors in dementia of Alzheimer type: a prospective study. Dementia 1990;1:52-5. [Unable to establish whether head injury in the cases occurred prior to the onset of $\mathrm{AD}$ ]

19. Pfeffer-Baczuk A, Barcikowska M, Luczywek E. [Risk factors in Alzheimer's disease]. [Polish]. Wiadomosci Lekarskie 1994;47:31-4.

20. Salib E. Risk factors in clinically diagnosed Alzheimer's diseases: a retrospective hospital-based case control study in Warrington. Aging $\theta$ Mental Health 2000;4:259-67. [Data collection was not symmetrical]

21. Salib E, Hillier V. Head injury and the risk of Alzheimer's disease: a case control study. Int J Geriatr Psychiatry 1997;12:363-8. [Case and control subjects were not matched. Controls were recruited from a psychiatric department]

22. Shalat SL, Seltzer B, Pidcock C, et al. Risk factors for Alzheimer's disease: a case-control study. Neurology 1987;37:1630-3. [Considered 
severe head trauma but did not require a loss of consciousness. No formal examination of the controls to rule out dementia.]

23. Shen Y. [A case-control study of risk factors on Alzheimer's disease. Multicentre collaborative study in China]. [Chinese]. Chung-Hua Shen Ching Ching Shen Ko Tsa Chih [Chinese Journal of Neurology o Psychiatry] 1992;25:284-7. [Unable to establish the severity of the head injury. Unable to establish whether head injury in the cases occurred prior to the onset of $\mathrm{AD}]$

24. Soininen H, Heinonen OP. Clinical and etiological aspects of senile dementia. Eur Neurol 1982;21:401-10. [Data collection was not symmetrical. Unable to establish the severity of the head injury, diagnostic criteria, and whether head injury in the cases occurred prior to the onset of $\mathrm{AD}]$

25. Sullivan P, Petitti D, Barbaccia J. Head trauma and age of onset of dementia of the Alzheimer type. JAMA 1987;257:2289-90. [Unable to establish the severity of the head injury or whether there was a formal examination of the controls to rule out dementia]

26. Tang MX, Maestre G, Tsai WY, et al. Effect of age, ethnicity, and head injury on the association between APOE genotypes and Alzheimer's disease. Ann N Y Acad Sci 1996;80:6-15. [Presents the same data as reported by Mayeux et al (1995)]

27. Tang M, Liu X, Yunyang. Risk factors for Alzheimer's disease in community: a population-based case control study. [Chinese]. Chinese Mental Health Journal 2001;15:22-5. [Data collection was not symmetrical. Did not exclude head injury that occurred after the onset of AD. Set "age periods" to provide a time frame within which incidents of head injury occurred for both cases and controls]

28. Wang PN, Wang SJ, Hong CJ, et al. Risk factors for Alzheimer's disease: a case-control study. Neuroepidemiology 1997;16:234-40. [Unable to establish the severity of the head injury, whether data collection was symmetrical, and if head injury in the cases occurred prior to the onset of $\mathrm{AD}]$

\section{Authors' affiliations}

S Fleminger, D L Oliver, A Giora, Lishman Brain Injury Unit, Maudsley Hospital, London, UK

S Lovestone, Section of Old Age Psychiatry, Institute of Psychiatry, London, UK

S Rabe-Hesketh, Department of Biostatistics and Computing, Institute of Psychiatry, London, UK

\section{REFERENCES}

1 Graves AB, White E, Koepsell TD, et al. The association between head trauma and Alzheimer's disease. Am J Epidemiol 1990;131:491-501.

2 Rasmusson DX, Brandt J, Martin DB, et al. Head injury as a risk factor in Alzheimer's disease. Brain Injury 1995;9:213-19.

3 Shalat SL, Seltzer B, Pidcock C, et al. Risk factors for Alzheimer's disease: a case-control study. Neurology 1987;37:1630-3.

4 Broe GA, Henderson AS, Creasey $\mathrm{H}$, et al. A case-control study of Alzheimer's disease in Australia. Neurology 1990:40:1698-707.

5 Mortimer JA, Van Duijn CM, Chandra V, et al. Head trauma as a risk factor for Alzheimer's disease: a collaborative re-analysis of case-control studies. Int J Epidemiol 1991;20(suppl 2):S28-35

6 Amaducci LA, Fratiglioni L, Rocca WA, et al. Risk factors for clinically diagnosed Alzheimer's disease: a case-control study of an Italian population. Neurology 1986;36:922-31

7 Chandra V, Kokmen E, Schoenberg BS, et al. Head trauma with loss of consciousness as a risk factor for Alzheimer's disease. Neurology 1989;39:1576-8.
8 Chandra V, Philipose V, Bell PA, et al. Case-control study of late onse "probable Alzheimer's disease". Neurology 1987;37:1295-300.

9 Ferini-Strambi L, Smirne S, Garancini P, et al. Clinical and epidemiological aspects of Alzheimer's disease with presenile onset: a case control study. Neuroepidemiology 1990:9:39-49.

10 Forster DP, Newens AV, Kay DWK, et al. Risk factors in clinically diagnosed presenile dementia of the Alzheimer type: a case-control study in northern England. J Epidemiol Community Health 1995;49:253-8.

11 Fratiglioni L, Ahlbom A, Viitanen M, et al. Risk factors for late-onset Alzheimer's disease: a population-based, case-control study. Ann Neurol 1993:33:258-66.

12 Li G, Shen YC, Li YT, et al. A case-control study of Alzheimer's disease in China. Neurology 1992;42:1481-8

13 Lindsay J, McDowell I, Hill G, et al. The Canadian Study of Health and Aging: risk factors for Alzheimer's disease in Canada. Neurology 1994:44:2073-80.

14 Mortimer JA, French LR, Hutton JT, et al. Head injury as a risk factor for Alzheimer's disease. Neurology 1985;35:264-7.

15 O'Meara ES, Kukull WA, Sheppard L, et al. Head injury and risk of Alzheimer's disease by apolipoprotein E genotype. Am J Epidemiol 1997; 146:373-84.

16 Tsolaki M, Fountoulakis K, Chantzi E, et al. Risk factors for clinically diagnosed Alzheimer's disease: a case-control study of a Greek population. Int Psychogeriatr 1997;9:327-41

17 van Duijn CM, Tanja TA, Haaxma R, et al. Head trauma and the risk of Alzheimer's disease. Am J Epidemiol 1992;135:775-82.

18 Rothman KJ. Modern epidemiology. Boston: Little, Brown and Company, 1986

19 StataCorp. Stata Statistical Software: release 7. College Station, TX 2001.

20 Stein DG. Brain damage, sex hormones and recovery: a new role for progesterone and estrogen? Trends Neurosci 2001;24:386-91.

21 Roof RL, Hall ED. Gender differences in acute CNS trauma and stroke: neuroprotective effects of estrogen and progesterone. J Neurotrauma 2000; 17:367-88

22 Bramlett HM, Dietrich WD. Neuropathological protection after traumatic brain injury in intact female rats versus males or ovariectomized females. J Neurotrauma 2001;18:891-900.

23 Melton L. What can sex hormones do for the damaged brain? Lancet $2001 ; 358: 818$

24 Henderson VW. The epidemiology of estrogen replacement therapy and Alzheimer's disease. Neurology 1997;48(5 suppl 7):S27-35.

25 Birge SJ, Mortel KF. Estrogen and the treatment of Alzheimer's disease. Am J Med 1997;103:36S-45S.

26 Mayeux R, Ottman R, Maestre G, et al. Synergistic effects of traumatic head injury and apolipoprotein-epsilon 4 in patients with Alzheimer's disease. Neurology 1995;45:555-7.

27 Plassman BL, Havlik RJ, Steffens DC, et al. Documented head injury in early adulthood and risk of Alzheimer's disease and other dementias. Neurology 2000;55: 1158-66.

28 Mehta KM, Ott A, Kalmijn S, et al. Head trauma and risk of dementia and Alzheimer's disease: The Rotterdam Study. Neurology 1999;53:1959-62.

29 Nemetz PN, Leibson C, Naessens JM, et al. Traumatic brain injury and time to onset of Alzheimer's disease: a population-based study. Am J Epidemiol 1999;149:32-40.

30 Williams DB, Annegers JF, Kokmen E, et al. Brain injury and neurologic sequelae: a cohort study of dementia, parkinsonism, and amyotrophic lateral sclerosis. Neurology 1991;41:1554-7.

31 Lye TC, Shores EA. Traumatic brain injury as a risk factor for Alzheimer's disease: a review. Neuropsychol Rev 2000;10:115-29.

32 Rimm AA. Re: "A case-control study of dementia of the Alzheimer type". Am J Epidemiol 1986;1 23:753-4.

33 Salib E, Hillier V. Head injury and the risk of Alzheimer's disease: a case control study. Int J Geriatr Psychiatry 1997;12:363-8.

34 Niino N, lijima S, Mizoguchi T, et al. [A case-control study of clinically diagnosed Alzheimer type dementia]. [Japanese]. Nippon Ronen Igakkai Zasshi [Japanese Journal of Geriatrics] 1990;27:693-8.

35 Heyman A, Wilkinson WE, Stafford JA, et al. Alzheimer's disease: a study of epidemiological aspects. Ann Neurol 1984;15:335-41.

36 Kondo K, Yamashita I. A case-control study of Alzheimer's disease in Japan: association with inactive psychosocial behaviours. In: Hasegawa $\mathrm{K}$, Homma K, eds. Psychogeriatrics, biomedical and social advances. Amderstam: Excerpta Medica, 1990. 